\title{
EXPRESSÃO ARTÍSTICA DE 911 DE LADY GAGA EM INTERFACE COM O DEBATE EM PSICOLOGIA E SAÚDE MENTAL: UMA REVISÃO DE LITERATURA
}

\author{
ARTISTIC EXPRESSION OF 911 BY LADY GAGA IN INTERFACE WITH THE DEBATE IN \\ PSYCHOLOGY AND MENTAL HEALTH:
}

A LITERARY REVIEW

\section{Isaac Marlon Vasconcelos do Nascimentoa, Clyvia Maria Vieira Borgesa, Luan Duarte Romãoa, Francisco Francinete Leite Júnior ${ }^{a, b}$}

\author{
Centro Universitário Dr. Leão Sampaio - UNILEÃOa \\ Universidade Católica do Pernambuco - UNICAPb \\ E-mail: isaac.8115@hotmail.com
}

\begin{abstract}
RESUMO
A cantora Lady Gaga, surge em setembro de 2020 com o single audiovisual 911 que pertence ao álbum Chromática, apresentando um debate sobre saúde mental, sobre psicofarmacologia, reforma psiquiátrica e surto psicótico, além de apresentar questões sobre a implicância de profissionais de saúde para o debate e para a emergência em saúde mental. Dessa forma, a presente pesquisa tem por objetivo compreender a importância da expressão artística do trabalho audiovisual 911 da cantora Lady Gaga para a Psicologia. Metodologicamente, trata-se de um estudo investigativo, a partir de uma revisão de literatura narrativa, com base em periódicos indexados nas bases acadêmicas: Google Acadêmico (Scholar Google), SCIELO (Scientific Electronic Library Online) e Periódicos da CAPES (Coordenação de Aperfeiçoamento de Pessoal de Nível Superior), usando os marcadores: Lady Gaga, 911, saúde mental, psicologia e arte, buscando primeiramente de cada descritor de forma individual, e depois conectando-os, sendo selecionados um total de 209 achados, e a posteriori descartados 113 por trazerem informações repetidas. A pesquisa resulta em temáticas de extrema relevância para a Psicologia como o debate em saúde mental, o debate sobre a emergência presente no clipe e a arte como forma de expressar esse debate em interface com a psicologia. Conclui-se que o trabalho da cantora tensiona debates e reflexões sobre assuntos como medicalização, sofrimento psíquico, ajuda psicológica, dentre outros, que se relacionam diretamente com a atuação profissional do psicólogo no campo da saúde mental.
\end{abstract}

Palavras-chave: Arte; saúde mental; psicologia.

\section{ABSTRACT}

The singer Lady Gaga, appears in September 2020 with the audiovisual single 911 that belongs to the album Chromática, presenting a debate on mental health, on psychopharmacology, psychiatric reform and psychotic outbreak, in addition to presenting questions about the implications of health professionals for the debate and for the emergency in mental health. Thus, this research aims to understand the importance of the artistic expression of the audiovisual work 911 by singer Lady Gaga for Psychology. Methodologically, this is an investigative study, based on a review of narrative literature, based on journals indexed in academic databases: Academic Google (Scholar Google), SCIELO (Scientific Electronic Library Online) and CAPES Journals (Coordination for Improvement of Higher Education Personnel), using the markers: Lady Gaga, 911, mental health, psychology and art, searching first of each descriptor individually, and then connecting them, being selected a total of 209 findings, and later discarded 113 for bringing repeated information. The research results in themes of extreme relevance to Psychology, such as the debate on mental health, the debate on the emergency present in the clip and art as a way of expressing this debate in an interface with psychology. It is concluded that the singer's work raises debates and reflections on issues such as medicalization, psychological distress, psychological help, among others, which are directly related to the professional role of the psychologist in the field of mental health.

Keyword: Art; mental health; psychology. 


\section{INTRODUÇÃO}

$\mathrm{Na}$ busca por se conectar com o público, os artistas procuram expressar em suas produções sentimentos e emoções presentes em seu cotidiano. No universo da música, versos, estrofes e rimas são formas desses profissionais compartilharem com o mundo certos momentos, situações e pautas pessoais. Uma das artistas que se destacou por tal feito no ano de 2020, foi a cantora Stefani Joanne Angelina Germanotta, popularmente conhecida como Lady Gaga. Na literatura científica podese citar diversos autores que introduzem a temática que vão sendo apresentados conforme as informações vão sendo trazidas à tona.

Conforme Bianchini (2015), Lady Gaga ganhou espaço na mídia global, através de sua defesa das minorias, tornando-se uma nova figura excêntrica responsável por uma renovação da música pop atual, que mistura elementos de outras décadas nas diversas produções que possui. Em sua "arte", a cantora apresenta o imaginário e o excêntrico, num universo surreal mesclado pelo lúdico e pela teatralidade, no qual, os fãs são convocados para outros lugares e "não lugares", numa mescla de elementos realistas (GAMA,2012). É nessa perspectiva que surge seu sexto álbum de estúdio, intitulado Chromatica (2020), que, conforme Lady Gaga (2020), traz à tona um tema recorrente no campo da psicologia e bastante íntimo para si: a saúde mental. Através de batidas dançantes de música pop, o disco apresenta letras que exploram traumas e transtornos mentais como a depressão, a ansiedade e a bipolaridade.

Uma das canções que aborda bem a temática é a oitava faixa do álbum, 911, que conforme relatou gaga (2020): "é sobre um medicamento antipsicótico que tomo, porque não consigo controlar o que o meu cérebro faz, eu sei disso e tenho que tomar o remédio para o processo ocorrer" (Apple Music, 2020). O título faz referência ao número de emergência dos Estados Unidos e a composição é narrada através de um efeito robótico na voz e na mixagem do som. Já o curta-metragem da música, conforme o publicitário e youtuber Spartakus Santiago (2020), usa várias metáforas e alegorias para poder criar uma obra que busca desestigmatizar o uso de medicamentos para a saúde mental. Para ele, a obra representa de forma artística e não literal, o subconsciente da cantora enquanto ela está em coma devido um acidente, ou seja, o clipe seria uma releitura abstrata em torno das imagens que ela presenciou no decorrer do acontecimento desagradável.

Ambas as produções (letra e curta-metragem da canção) expressam a relação da artista com a saúde mental, temática que tem ganhado mais visibilidade no
Brasil e no mundo. Um exemplo significativo foi o tema da redação do último Exame Nacional do Ensino Médio (2020), ter sido "O estigma associado às doenças mentais na sociedade brasileira" (Brasil,2021). Outro fato notável, é a campanha nacional intitulada "Janeiro Branco", com o objetivo chamar a atenção da sociedade para as questões relacionadas à Saúde Mental (CVV, 2021). Assim, entendemos que esses pequenos avanços têm contribuído no debate sobre o assunto, e a manifestação artística da cantora em 911, traz um enfoque e reflexões importantes sobre a pauta.

Nessa lógica, a presente pesquisa tem como objetivo e questionamento principal compreender: "Qual a relevância das referências e da expressão artística de 911 de Lady Gaga para o debate em Psicologia e Saúde Mental?". Nos guiamos por esse questionamento, percebendo a importância de analisar a realidade contemporânea, a qual também é expressada por artistas seja da música, do cinema, do teatro, da pintura, como Lady Gaga. Além disso, o estudo tem como foco traçar um breve histórico sobre a relação entre saúde mental, psicologia e arte, e explicitar a articulação da canção com temáticas do campo da psicologia e da saúde mental. A letra e curta-metragem, são percebidos como relevantes para debates contemporâneos nas áreas já citadas, que ficará mais explícito nos resultados e discussões posteriormente. Nosso intuito é corroborar com princípios éticos dispostos como fundamentais no Código de Ética Profissional do Psicólogo (2005), onde regulamenta ser fundamental a crítica social e a contribuição da promoção de saúde ao ser humano.

\section{METODOLOGIA}

Metodologicamente, a presente pesquisa trata-se de um estudo investigativo, a partir de uma revisão de literatura narrativa, com base em periódicos indexados nas bases acadêmicas: Google Acadêmico (Scholar Google), SCIELO (Scientific Electronic Library Online) e Periódicos da CAPES (Coordenação de Aperfeiçoamento de Pessoal de Nível Superior), resultando em um total de 209 periódicos encontramos nos três buscadores, e então descartados 113 dos 209, possibilitando um recorte temporal de artigos/estudos de anos de 1974 a 2020, sendo a maioria deles em português, utilizando como descritores: Lady Gaga, 911, saúde mental, psicologia e arte. Os critérios utilizados para inclusão dos artigos foi embasamento teórico com autores inseridos na psicologia, coesão com o posicionamento ético do psicólogo na atualidade e aspectos interseccionados referentes à obra audiovisual e da letra da música estudada. Além disso, usufrui-se de notícias de jornais, artigos de sites, podcasts, 
vídeos do youtube, e sobretudo, de uma minuciosa e crítica leitura da letra da música e atenção aos detalhes e às referências do clipe e curta-metragem " 911 ", presente no álbum Chromatica, da cantora norte-americana Lady Gaga. Foi selecionado cerca de 96 periódicos, em uma busca onde os marcadores foram selecionados separadamente e depois de dois em dois, sendo lidos após assistir minuciosamente o vídeo clipe da cantora. Contudo, foram sendo inseridos os periódicos dentre os selecionados de acordo com a necessidade e a direção à qual a pesquisa apontava.

\section{DESENVOLVIMENTO}

\section{O TRABALHO AUDIOVISUAL DE 911}

Conforme Gabriel,Gatti (2020), integrante do Grupo de Pesquisa em Estética e Crítica Cultural Persona, o curta-metragem de 911, é uma obra promissora na carreira de Lady Gaga. Conforme a equipe, o debate sobre saúde mental que a cantora apresenta na letra se manifesta e é bem referenciado no vídeo através de uma mensagem inspiradora. Inicialmente, o clipe apresenta muitas dúvidas, mas no final descobre-se que as cenas anteriores não passavam de um delírio da artista, enquanto a mesma encontrava-se em estado de saúde crítico devido a um acidente.

Conforme Santiago (2020), o curta-metragem começa em um deserto onde a cantora está jogada no chão. Após acordar vedada, ela é guiada por um cavaleiro preto, que significa a morte, até um oásis. Nesse local, os elementos e personagens são mostrados através de metáforas entre o delírio da cantora e os acontecimentos reais. Dessa forma, a venda e a tornozeleira que Lady Gaga possui seriam representações lúdicas dos ferimentos sofridos nos mesmos locais. O homem que é visto batendo sua cabeça repetidas vezes numa almofada, é a representação do airbag sendo disparado. Outro participante com ornamentos dourados recebendo uma concha, simboliza o homem rico da Ferrari que ganha oxigenação dos bombeiros. A mulher que surge com ornamentos roxos envolvida em um corpo embalsamado, faz alusão à vítima fatal do acidente que se encontra morta no colo dessa mesma intérprete chorando. As pessoas curiosas com toda a situação são representadas pelos ornamentos azuis e branco, alusão aos jeans que usam. São eles uma figurante que encara a cantora no começo do clipe e um casal com o pau-de-selfie registrando toda a tragédia. Conforme o autor citado, os policiais são simbolizados pelas figuras grandes em roupas azul escuro. Enquanto os bombeiros utilizam roupas laranjas e amarelas, sendo vistos em inúmeras cenas, como segurando o estande que Lady Gaga se coloca no centro, no caso, uma alusão às cenas onde carregam a porta do carro no cenário.

Posteriormente, dois personagens que representam os paramédicos são vistos chegando com uma sombrinha girando, sendo uma alusão ao helicóptero que pousou no local do acidente. Enquanto isso, Lady Gaga é vista tentando subir aos céus, até ser puxada de volta por uma corda atada ao seu pé, representando que os profissionais tentavam mantê-la viva no mundo real. Uma delas, estava com uma lanterna examinando os olhos da artista, enquanto no delírio ela aparecia com um espelho. O Caduceu, símbolo da medicina estampado em seu uniforme, foi traduzido na imaginação da cantora de forma literal, ou seja, por uma cobra. Após aterrissar na superfície, o outro paramédico envolve seu tornozelo no universo lúdico, apontando que essa seria a representação do torniquete sendo atado no mundo real, estancando o sangramento. Em seguida, são tentadas mais duas medidas socorristas: respiração boca-a-boca, na qual a cantora rejeita; e por fim, a desfibrilação, significando que após ser atada a maca e receber sua sentença final, ela volta à vida real (SANTIAGO,2020). Ademais, conforme a Revista Vogue (2020):

"Todos esses elementos atraentes culminam em uma revelação ascendente: a cena é um sonho construído de fatores circundantes, induzido após Gaga perder a consciência em um acidente de carro. "Eu não tinha minhas pílulas", soluça Gaga enquanto paramédicos tentam acalmá-la. (REVISTA VOGUE,2020)

Em declaração numa de suas redes sociais, a artista escreveu que o produto era algo muito pessoal para ela, seria sua experiência com a saúde mental e a forma como a realidade e o sonho podem se interconectar para formar heróis dentro e envolta dos sujeitos (GAGA, 2020).

Ademais, na trama, a artista usa vários elementos da cultura armênia, como símbolos e vestimentas, além de elementos estéticos. Logo no início do vídeo a referência fica clara, já que em cena encontra-se a bicicleta quebrada e as romãs no chão, simbolizando o filme "A cor da Romã" (The Colour of Pomegranates) (1968), de Serguei Paradjanov, que inspirou o curta-metragem conceitualmente. Para Steil (2019), mesmo que essa obra cinematográfica se trate da vida e morte do poeta armênico, a história também pode ser entendida como "um relato e homenagem a região da transcaucásia, celebrando a música, o folclore, a arquitetura e costumes de seu povo, com ênfase na Armênia" (STEIL,2019, p.21). 


\section{SAÚDE MENTAL, PSICOLOGIA E ARTE: UM BREVE DEBATE}

Para além da criação de novos serviços substitutivos ao hospital psiquiátrico, é necessário libertarmo-nos de nossos manicômios mentais (PELBART, 1993), dessa forma, a arte pode ser instrumento para esta libertação, pois a experiência sensível propiciada por ela manifesta-se como um acontecimento, como potência de desestabilização das formas já postas. Seu poder de afetação extravasa o produto final, colocando em devir os fluxos que atravessam tanto o artista, como quem a contempla efetivamente (Deleuze \& Guattari, 1992). Liberato e Dimestein, em seu estudo intitulado "Arte, Loucura e Cidade: A Invenção de Novos Possíveis" (2013), defendem a proposta da arte: "como vetor de subjetivação, dispositivo desinstitucionalizante, estratégia de resistência, criador de agenciamentos que desconstruam estigmas e possibilitem a invenção de territórios existenciais singulares e de outros caminhos em direção à alteridade" (LIBERATO, DIMESTEIN, 2013, p. 272).

Foucault (1995) aponta que, nos hospitais no mundo árabe no século XII, que foram destinados exclusivamente aos loucos: a música, a dança, os espetáculos e as narrativas de contos fabulosos eram meios de intervenção e de cura da alma. Já na Europa, durante o Renascimento, o interesse pela loucura era infiltrado em todas as esferas da vida cultural e na arte em especial. Segundo Lima e Pelbart (2007, p. 22), este pode ter sido o primeiro marco onde as artes, em especial a música, tinham aí virtudes terapêuticas que atuavam na totalidade do ser humano, penetrando-lhe corpo e alma. Embasandose nessa perspectiva para o âmbito da Saúde Mental, podese dizer que a presente pesquisa defende o movimento da "Reforma Psiquiátrica", que busca "uma sociedade realmente igualitária e humana, primando pela reinserção social dos excluídos, como são os loucos, baseando-se nos princípios de liberdade, igualdade e fraternidade, por uma sociedade livre da opressão, preconceito e ignorância”.

$\mathrm{O}$ que a cantora Lady Gaga fez no trabalho audiovisual de 911 foi o que Alverga e Dimenstein (2006, p. 305) chamariam de "desconstruir práticas e discursos que naturalizam e reduzem a loucura à doença mental", que também segue a perspectiva de Paiva (2003) sobre a saúde mental ser um campo que está intimamente ligado com a reforma psiquiátrica e do direito à loucura.

Um elemento importante dentro do debate da saúde mental que aparece fortemente como chave ao objetivo da presente pesquisa é a arteterapia, que bebe de áreas do conhecimento com a Psicanálise Freudiana, que, no século XX, passou a interessar-se pela arte como meio de manifestação do inconsciente através de imagens. Freud (1974) percebeu que o artista pode simbolizar concretamente o inconsciente em sua produção, trazendo à tona conteúdos do psiquismo. Um exemplo disso são seus estudos realizados sobre as obras de autores consagrados como Leonardo da Vinci e Michelangelo (FREUD, 1974). A arte e a cultura são aqui consideradas peças de estratégias no campo da saúde, voltadas à produção de subjetividade, construção de projetos de vida e reconstrução da cidadania dos sujeitos, pois o cuidado em saúde mental requisita dos profissionais a experiência estética e cultural (CASTRO, LIMA, BRUNELLO, 2001).

Outro elemento importante dentro do clipe da cantora e que também é debate da área de Psicologia é a forma como é exposto na obra audiovisual a "Psicologia das Emergências e Desastres". Para Bindé e Carneiro (2001), a ideia de desastre é ampla e imprecisa, pois devem ser levados em conta o contexto econômico, político e social em que ele ocorre. Segundo esses autores, todas essas variáveis estão em paralelo com o comportamento das pessoas envolvidas e será o resultado de como essas instâncias estão configuradas. Os debates sobre a psicologia das emergências e dos desastres (MOLINA, 1994), que ganhou destaque recentemente com mais força, é definida como aquela área da psicologia geral que estuda as diferentes mudanças e os fenômenos pessoais presentes em uma catástrofe, seja esta natural ou provocada pelo homem, que resulta em grande número de mortos ou feridos que tendem a sofrer sequelas por toda a vida (MOLINA, 1994).

\section{RESULTADOS E DISCUSSÕES}

Mediante os descritores e os dois eixos desenvolvidos por esta pesquisa, expostos acimas, que diz respeito ao trabalho audiovisual da cantora Lady Gaga: 911 (objeto de estudo da pesquisa) e o debate em saúde mental com elementos artísticos que também foram apresentados cientificamente, pode-se dizer que os tópicos se conectam e fazem jus à Psicologia e à Saúde Mental, especialmente, ao que ela se propõe a debater, como é apresentado nos aportes teóricos apresentados abaixo que entram em discussão.

Apesar dos inúmeros tabus, o debate sobre saúde mental tem ganhado cada vez mais visibilidade na atualidade. A temática tem sido mais abordada em escolas, nas famílias e principalmente nas redes sociais. Conforme Alves e Rodrigues (2010), o panorama sobre a terminologia tem se tornado mais abrangente, numa lógica que o conceito de saúde mental vai além da ausência de doença ou enfermidade, sendo assimilada como o produto 
de complexas interações, que incluem fatores biológicos, psicológicos e sociais. Além disso, muitos artistas e personalidades da mídia vem expondo suas relações com transtornos mentais como a ansiedade e a depressão, o que acaba possibilitando uma percepção mais ampla sobre o tema. Uma dessas é a cantora Lady Gaga, que no lançamento do seu último álbum, Chromatica, fez uma jornada sobre sua saúde mental, deixando mais explícito essa relação na canção.

De forma geral, a letra e o clipe da música analisada neste trabalho, expressam o sofrimento psíquico vivenciado por Lady Gaga. Safra (2004), defende que o fenômeno da globalização pode fazer surgir tais problemáticas, apresentando situações e problemas que comprometem o sujeito em sua possibilidade de ser, fragmentando-o. Diante desse processo, o indivíduo se vê descentrado de si mesmo e impedido de encontrar amparo para superar as dificuldades psíquicas. Conforme, Cambuí (2013), revisando as obras de Ehrenberg (2009), isso quer dizer que:

"As mudanças pelas quais a sociedade ocidental
atual vem passando, promovem alterações
paradigmáticas referentes à pluralidade dos
valores e ao esvaziamento dos referenciais, e não
da ausência deles. O sujeito, submerso em meio à
polissemia de sentidos, estimulações excessivas e
cobranças inalcançáveis, se vê acometido pelo
sentimento de insuficiência, impotência, fracasso,
vazio, baixa auto-estima e falta de sentido na vida.
Estas manifestações traduzem o temor do ser
humano de não estar à altura das exigências e de
estar condenado eternamente à incapacidade,
insuficiência e à fadiga constante de ser si
mesmo" (CAMBUÍ, 2013, p.30).

São elementos que são debatidos no trabalho audiovisual da cantora a partir de suas cenas, que elucidam sofrimento e confusão mental a partir do momento que o eu-lírico do trabalho entra dentro de seus delírios. Desse modo, com o aparecimento desses sofrimentos e adoecimentos, surgem novos desafios teórico-práticos para o profissional da psicologia, que tem o intuito de oferecer suporte terapêutico aos seus pacientes, para a superação dessas adversidades, ou seja, a alta incidência de novas formas de sofrimento emocional, passa a exigir manejos específicos que dêem sustentação ao sofrimento psíquico que atinge o homem (CAMBUÍ,2013)

Uma das questões abordadas pela cantora na música é a necessidade de usar medicamentos para ficar bem, tentando delimitar sua relação de amor e ódio com o antipsicótico. Seu discurso corrobora com o panorama da sociedade atual, no qual os fatores socioculturais e étnicos se sobrepõem aos fatores comportamentais, biológicos e psicológicos que norteiam a utilização de psicofármacos ao promover aos indivíduos a visualização da utilização desses produtos como forma imediatista e indolor de anular seus agravos e inquietações, ao conceber o corpo como uma máquina, nutrindo a necessidade de alívio do sofrimento psíquico de maneira instantânea (BEUX, 2015). Além do mais, a relação conturbada do indivíduo retrata bem a vivência daqueles que estão em processo de adaptação ao tratamento psicofarmacológico. Conforme afirma Xavier (p.324, 2014):

"A utilização regular dos psicofármacos
representa um dos maiores desafios no tratamento
das pessoas com transtornos mentais. As causas
da rejeição à medicação variam de acordo com as
singularidades dos indivíduos, mas,
frequentemente, devem-se aos efeitos colaterais
desagradáveis, que afetam vários aspectos da vida
pessoal, ou a não aceitação do uso diário destes
fármacos, por um período prolongado de tempo".

Um ponto central elucidado pela artista são os estados adoecidos da sua mente, ou seja, os distúrbios mentais que ela vivencia. Estes, podem ser definidos como "uma vasta gama de problemas, com diferentes sintomas. No entanto, normalmente são caracterizados por uma combinação de pensamentos, emoções, comportamentos e relacionamentos anormais com outros" (Fundação Torino,2018,p.9). Já na primeira estrofe os versos: "Mudando de entorpecentes emocionais/Continuo repetindo frases de ódio próprio/Já ouvi o suficiente dessas vozes/Quase como se eu não tivesse escolha”, explicitam o processo de autossabotagem, no qual seus próprios pensamentos estão aprisionados, o que provoca a capacidade de se odiar.

Além disso, a canção aponta ao longo de seu desenvolvimento para uma constância de sintomas psíquicos sofridos pela cantora que vão das ideias de autodesvalorização e culpa a uma demonstração prévia de humor depressivo. Já que, ela descreve a relação sombria que seu humor traz e a ânsia em conseguir sair dessa situação, conforme elege a si mesma a sua maior inimiga. Os deprimidos costumam aludir ao sentimento de que o intenso desejo de pôr fim a um estado emocional extremamente penoso que se configura como interminável (DEL PORTO, 1999). "Meu humor está indo para lugares maníacos/Gostaria de rir e continuar com boas amizades/Me aguarde vida, aqui vou eu de novo". O que nos leva a refletir sobre como esses transtornos se manifestam e podem ser percebidos pelo psicólogo, que consequentemente ampara o sujeito nesses processos. Conforme Bock, Furtado e Teixeira (1999), a ajuda 
terapêutica traz suporte e favorece a compreensão dos conteúdos internos que causam o transtorno no sujeito. Consequentemente, pode levar o indivíduo a uma reestruturação pessoal dos seus valores e projeto de vida, além de possibilitar a convivência com insatisfações e perdas.

Em outra parte, a cantora expõe o sentimento comum entre pessoas que estão sob uso de medicação que é a apatia. "Não consigo me ver chorar/ Não pode me ver chorar nunca mais". Esse sentimento é também uma forma de atitude, a qual suga as energias ao ponto que o sujeito se sente letárgico e muitas vezes paralisado, sem vontade ou perspectiva de fazer o que precisa, reforçando o cansaço mental como em um ciclo vicioso. Isso nos revela indícios do transtorno de Lady Gaga, pois conforme a Organização Mundial de Saúde (2001):

A depressão caracteriza-se por tristeza, perda de interesse nas atividades e diminuição da energia. Outros sintomas são a perda de confiança e autoestima, o sentimento injustificado de culpa, ideias de morte e suicídio, diminuição da concentração e perturbações do sono e do apetite. Podem estar presentes também diversos sintomas somáticos. (ORGANIZAÇÃO MUNDIAL DE SAÚDE, 2001)

A cantora também nos leva a refletir sobre o sentimento de culpa que os sujeitos em sofrimento psíquico se vêem, muitas das vezes reforçado pelos discursos de julgamento de parte da sociedade, que não dá a devida importância ao tema da saúde mental. Para Rocha, Hara e Paprocki, (2015), esse estigma seria uma grande barreira para portadores de transtornos mentais, já que sofrem constante descriminação por parte de familiares, amigos e colegas. Além disso, os autores pontuam que os meios de comunicação os retratam de forma pejorativa e caricata, gerando um processo de autoestigma, no qual o indivíduo internaliza tais visões sobre si. "Há comprometimento da autoestima, mais incapacitação e menos resistência ao estresse. Tudo isso acarreta piora clínica e reinício do círculo vicioso" (p. 593). O que reflete também a visualização da cultura contemporânea, que deixa a cargo do indivíduo (por obrigação) as regras de funcionamento da própria vida e a rejeição à interferência coletiva nos destinos individuais. Esse processo de privatização fez com que a autogestão passasse a ser a principal atividade do indivíduo que traz apenas para si a responsabilidade da não adequação ao ideal do indivíduo não-doente (PEREIRA, 2015).

Já em seguida, quando ela diz "Disque 911, e então depois tome outro tipo de ajuda", percebemos a importância de buscar primeiramente ajuda especializada para a situação, contrariando as sentenças que os grupos sociais colocam sobre quem tem transtornos mentais. Isso quer dizer que "independentemente do seu espaço de atuação e de quem o contrata, o psicólogo deve sempre colaborar - preferencialmente de forma interdisciplinar e em equipes multiprofissionais - com a luta pela vida e saúde dos humanos" (SOUZA,2013).

Na letra da canção também podemos refletir sobre a vanglorização em torno dos medicamentos em decorrência do intenso sofrimento psíquico. Os versos "Mantenho minhas bonecas dentro de caixas de diamantes/As deixo lá até eu saber que vou derrubar/Essa parede que eu construí em torno do meu oásis/O paraíso está em minhas mãos", demonstram o poder das pílulas em criar um mundo perfeito e inibir o sujeito da dor profunda referida no início da canção, como também apontam para uma perda de noção da realidade devido o problema psicológico. Nessa lógica, podemos pensar que:

a Instituição médica provocaria uma espécie de dependência dos indivíduos aos medicamentos, médicos e hospitais, conduzindo a uma crise da individualidade face à doença e à morte e, por sua vez, o indivíduo já não poderia mais enfrentar a doença com todo seu recurso de potencialidades, havendo uma espécie de paralisia da autonomia dessas mesmas pessoas no enfrentamento da dor e do sofrimento Seguindo esta ideia, Cordeiro segue fazendo o leitor refletir sobre a expansão do consumo de medicamentos que configura uma lógica de transformação de outras demandas sociais ligadas, por exemplo, às condições de trabalho, vida familiar, conflitos de relações em demandas por cuidado médico (CORDEIRO,1980, apud SOUZA, 2017, p.10).

Ademais, essa visão exposta em relação a medicação revela a interiorização do sujeito acometido por sofrimentos psíquicos da visão midiática difundida na qual a medicação tem como meta é restituir a pessoa ao "estado pré-mórbido", ou seja, ao estado de personalidade anterior ao que foi considerado como doença (RODRIGUES, 2003). Desse modo, percebemos a era do imediatismo em que vivemos, na qual as pessoas não têm tempo para cuidar da saúde mental, pois o "progresso" trouxe um processo de suprimir as emoções, e o correto seria o controle e a racionalidade destas. Num movimento que essa postura traz reações radicais, devido os estados emocionais intensos não encontrarem expressão adequada, gerando doenças psicossomáticas e colocando os medicamentos, como a forma mais ágil de conseguir "resultados". (BRAGHIROLLI; BISI, RIZZON; NICOLETTO, 2009). Ainda assim, a canção não deixa 
explícito o uso do psicotrópico de forma negativa, mas nos tensiona a refletir até que ponto a medicalização é necessária, já que "existe a procura de uma espécie de "felicidade química", tão necessária à nossa existência como cidadão e consumidor no capitalismo" (PERUSSI, 2015, p.154).

Em suma, a canção aponta para a relevância do debate sobre o sofrimento psíquico e a importância de pedir ajuda. Lady Gaga demonstra que há possibilidade de tratamento e acolhimento para a dor que o transtorno causa. A artista naturaliza a discussão sobre as próprias dores, dando possibilidade de outras pessoas fazerem o mesmo e indo contra a lógica de retração dos sentimentos colada muitas vezes pela sociedade. Há um processo de ressignificação da saúde mental e do papel da psicologia nesse processo, no qual o público pode projetar a si mesmo e seus medos e, assim, transformar a visão social desse fenômeno, corroborando com a conceito de arte enquanto política por modificar a paisagem da vida coletiva (LIBERATO, DIMESTEIN, 2013). Pode-se dizer então que o trabalho artístico de 911 da cantora tem uma perfeita conexão com os achados teóricos que se propõe a debater a mesma temática que a cantora enfatiza de forma artística e que é importante para a compreensão e para a crítica social sobre o que acontece, algo que é preciso para a formação do psicólogo e elucidado fortemente nos princípios fundamentais do código de ética (CÓDIGO DE ÉTICA PROFISSIONAL DO PSICÓLOGO, 2005).

\section{CONSIDERAÇÕES FINAIS}

Mediante os fatos elencados, percebemos a importância do trabalho de Lady Gaga enquanto artista, tanto pela sua arte (música) quanto pelo produto decorrido dela (videoclipe), em relação aos debates em saúde mental na contemporaneidade. As críticas feitas pela cantora vão além da sua delimitação geográfica, se fazendo presente uma atenção sobre nossas emergências e dando ênfase a culpabilização e estigma social que o sujeito vítima de transtornos mentais carrega. A letra e o curta-metragem de 911, tensionam debates e reflexões sobre assuntos como medicalização, sofrimento psíquico, ajuda psicológica, dentre outros, que se relacionam diretamente com a atuação profissional do psicólogo no campo da saúde mental.

É importante mencionar que as formas artísticas e a performance usada pela cantora em sua "alucinação psicótica" foram elementos cruciais para uma percepção científica da responsabilidade social no cuidado, no acolhimento e na humanização no tratamento à saúde mental. Dessa forma, Lady Gaga traz à tona a importância de não termos vergonha de explorar as nossas dores e pedir ajuda. Assim, pode-se dizer que 911 vai muito além do que uma música pop com uma batida dançante.

As limitações da presente pesquisa precisam adentrar todo um corpo acadêmico e profissional no meio da saúde para que os profissionais e futuros profissionais entendam por meio de expressões artísticas o sofrimento psíquico e assim, poder promover uma intervenção em saúde de forma mais humanizada e acolhedora. A pesquisa deve ir desde biomédicos até assistentes sociais, passeando nos espaços de pesquisas em enfermagem, psicologia, fisioterapia, odontologia e demais áreas que estão em contato com o ser humano. Pode-se dizer então por meio dos descritores e os dois eixos desenvolvidos nesta pesquisa, expostos no desenvolvimento, que os tópicos se conectam e fazem jus à Psicologia e à Saúde Mental, especialmente, ao que ela se propõe a debater, como é apresentado nos aportes teóricos discutidos em contato com elementos da obra artística.

\section{REFERÊNCIAS}

ALVES, A. A. M.; RODRIGUES, N. F. R. Determinantes sociais e económicos da Saúde Mental. Revista Portuguesa de Saúde Pública, v. 28, n. 2, p. 127-131, 2010.

BEUX, M. T.; KUJAWA, I. Uso abusivo de psicofármacos: medicalização da vida e consequências psicossociais. In: IX Mostra de Iniciação Científica e Extensão Comunitária e VIII Mostra de Pesquisa de Pós-Graduação da IMED. 2015.
BIANCHINI, D. O discurso estético de Lady Gaga na contemporaneidade - São Paulo, 2015. 116 f.: il.; 30 cm. - Faculdade Cásper Líbero, Programa de Mestrado em Comunicação.

BOCK, A. M. B.; FURTADO, O.; TEIXEIRA, M. L. T. Psicologias: Uma Introdução à Psicologia. 13. ed. São Paulo: Saraiva, 1999.

BRAGHIROLLI, E. M.; BISI, G. P.; RIZZON, L. A.; NICOLETTO, Ugo. Psicologia Geral. 29a Ed. Petrópolis: 


\section{V.10 N.1 (2022) ISSN: $2317-434 X$}

Vozes, 2009

CAMBUÍ, H. A. Sofrimento psíquico contemporâneo: um estudo psicanalítico do imaginário coletivo de estudantes de psicologia. 2013. 177 f. Dissertação (mestrado) Universidade Estadual Paulista, Faculdade de Ciências, 2013.

CASTRO E. D.; LIMA, E. A; BRUNELlO, M. I. B. Atividades humanas e terapia ocupacional. In: De Carlo MMRP, Bartalotti CC, organizadores. Terapia ocupacional no Brasil: fundamentos e perspectivas. São Paulo: Plexus; 2001. p.41-59.

CENTRO DE VALORIZAÇÃO DA VIDA. JANEIRO BRANCO: QUEM CUIDA DA MENTE, CUIDA DA VIDA. CVV, 2021. Disponível em: https://www.cvv.org.br/blog/janeiro-branco-quem-cuidada-mente-cuida-da-vida >. Acesso em: janeiro de 2021.

DEL PORTO, J. A. Conceito e diagnóstico. Rev. Bras. Psiquiatr., São Paulo, v. 21, supl. 1,p. 06-11, May 1999 . Disponível em: http://www.scielo.br/scielo.php? script=sci_arttext\&pid=S151644461999000500003\&lng=en\&nrm=iso>. Acesso: 29 Jan. 2021.

FREUD, S. O Moisés de Michelangelo. In: Freud S. Edição standard brasileira das obras psicológicas completas de Sigmund Freud. Rio de Janeiro: Imago; 1974. v. 13. p. 249-79.

FUNDAÇÃO TORINO. Guia de Estudos OMS - Saúde mental. Belo Horizonte, 2018. Disponível em: < http://biblioteca.cofen.gov.br/wp-

content/uploads/2019/01/Guia-de-Estudos-OMS-

Sa\%C3\%BAde-Mental.pdf > . Acesso em: Janeiro de 2021

GAGA, L. The Chromatica Interview with Zane Lowe. Youtube. Disponível em: $\langle$ https://www.youtube.com/watch?v=CZXBF9t32zA>. Acesso em: 25 de outubro de 2020.

GAMA, M. G. Lady Gaga : um corpo além do corpo. Comunicação apresentada no II Seminário Internacional de pesquisa "Consumos Afetividade e Vínculos: a cidade, o lugar, o produto". Universidade de Minho - Portugal. 2012

GOVERNO FEDERAL Estigma da doença mental é tema da redação do Enem. GOV, 2021. Disponível em:<https://www.gov.br/inep/pt-

br/assuntos/noticias/enem/estigma-da-doenca-mental-e- tema-da-redacao-do-enem-2020. Acesso em: janeiro de 2021.

LIBERATO, M. T. C.; DIMENSTEIN, Magda. Arte, loucura e cidade: a invenção de novos possíveis. Psicol. Soc., Belo Horizonte , v. 25, n. 2, p. 272-281, 2013. Available from $<$ http://www.scielo.br/scielo.php?script=sci_arttext\&pid $=$ S0102-71822013000200004\&lng=en\&nrm=iso $>$. access on 06 Dec. 2020.

ORGANIZAÇÃO MUNDIAL DA SAÚDE. Relatório sobre a saúde no mundo 2001 - saúde mental: nova concepção, nova esperança. Geneva: Organização Mundial da Saúde, 2001.

PEREIRA, C. R. A construção da subjetividade contemporânea e sua relação com a depressão. Cadernos de psicanálise (Rio de Janeiro), v. 37, n. 32, p. 17-41, $2015 . \quad$ Disponível em <http://pepsic.bvsalud.org/scielo.php?script=sci_arttext\& pid=S1413-62952015000100002\&lng=pt\&nrm=iso >.

Acesso em: dezembro de 2020.

GATTI, G. Lady Gaga debate saúde mental através de um sonho conceitual em 911. Persona Crítica Cultural,2020. Disponível em: http://personaunesp.com.br/lady-gaga911-critica/ > . Acesso em: janeiro de 2021.

PERRUSI, A. Sofrimento psíquico, individualismo e uso de psicotrópicos: Saúde mental e individualidade contemporânea. Tempo soc. , São Paulo, v. 27, n. 1, pág. 139-159, junho de 2015. Disponível em $<$ http://www.scielo.br/scielo.php?script=sci_arttext\&pid $=$ S0103-20702015000100139\&lng=en\&nrm=iso $>$. acesso em: 22 de janeiro de 2021.

ROCHA, F. L.; HARA, Cláudia; PAPROCKI, Jorge. Doença Mental e Estigma. Revista Médica de Minas Gerais, v. 25, n. 4, p. 590-596, 2015.

RODRIGUES, J. T. A Mmedicação como única resposta: uma miragem do contemporâneo. Psicologia em Estudo, Maringá, v. 8, n.1, p.13-22, jan./jun. 2003; Disponível em: http://www.scielo.br/pdf/pe/v8n1/v8n1a03.pdf; Acessado em 01/12/2020.

SAFRA, G. Uma nova modalidade psicopatológica na pós modernidade: os espectrais. Psychê. Revista de psicanálise, São Paulo, v. 6, n. 6, p. 46, 2000.

SANTIAGO, S. O SIGNIFICADO OCULTO DE 911 
(Lady Gaga) - Análise. Youtube. Disponível em: <https://www.youtube.com/watch?v=fIfqd931LO0 Acesso em 10 de setembro de 2020.

SOUZA, J. C. Depressão, a medicalização, o mercado de antidepressivos e a busca de uma nova ação terapêutica. 2017. 41 f. Trabalho de Conclusão de Curso (Especialização em Gestão da Inovação em Fitomedicamentos) - Instituto de Tecnologia em Fármacos / Farmanguinhos, Fundação Oswaldo Cruz, Rio de Janeiro, 2017.

SOUZA, W. F. Transtornos mentais e comportamentais relacionados ao trabalho: o que a psicologia tem a dizer e a contribuir para a saúde de quem trabalha?. Fractal, Rev. Psicol., Rio de Janeiro, v. 25, n. 1, p. 99-108, 2013. Disponível em:

కhttps://www.scielo.br/scielo.php?script=sci_arttext

HYPERLINK ">. Acesso em:01 de dezembro de 2020.
STEIL ,Y. Aproximações entre Medeia Vozes e A Cor da >. Romã - Monografia (Bacharel em História da Arte) Instituto de Artes da Universidade Federal do Rio Grande do Sul. Rio Grande do Sul, 2019.

VOGUE. Lady Gaga Reveals the Personal Meaning Behind Her New Music VideO. VOGUE, 2020. Disponível em: <https://www.vogue.com/article/ladygaga-911-music-video-mental-health-chromatica>. Acesso em: 22 de janeiro de 2021.

XAVIER, M. S. et al . O significado da utilização de psicofármacos para indivíduos com transtorno mental em acompanhamento ambulatorial. Esc. Anna Nery, Rio de Janeiro, v. 18, n. 2, p. 323-329, June 2014 . Available from

<http://www.scielo.br/scielo.php?script=sci_arttext\&pid $=\mathrm{S} 14181452014000200323 \& \operatorname{lng}=\mathrm{en} \& \mathrm{nrm}=\mathrm{iso}>$. Acesso em: 15 Dezembro de 2020. 